\title{
MORPHODYNAMIC MODELING OF THE MEDIUM-TERM MIGRATION OF A TIDAL CHANNEL USING PROCESS-BASED MODEL
}

\author{
Diem Nguyen ${ }^{1}$, Talal Etri ${ }^{1}$, Karl-Heinz Runte ${ }^{1}$ and Roberto Mayerle ${ }^{1}$
}

\begin{abstract}
This paper investigates the predictive capability of a morphodynamic model in capturing the development of a tidal channel on the German North Sea coast which experienced migration in the last few years. A depth-averaged version of a process-based model, Delft3D, is used. A description of the set-up, calibration and validation of the process-based models is presented. Field measurements with a dense spatial and temporal coverage were used for the development of the models. Results from the hydrodynamic and sediment transport simulations were in agreement with observations. The morphodynamic model simulations were speeded up with a morphological acceleration factor in conjunction with a representative period. Results of model calibration and validation covering periods of several years proved the capability of the model to reproduce the migration of the tidal channel. According to the standards usually adopted for checking the accuracy of morphodynamic models, the performance of the model presented here was quite good. The model ability in predicting the migration in the medium-term was found to be dependent primarily on the accuracy of the starting bathymetry, characteristics of the substrata and of the mud sediment fraction as well as on the selection of the representative period. A reduction in the rate of migration of the tidal channel is predicted from 2008 till 2010.
\end{abstract}

Keywords: tidal channel migration; process-based model; morphological factor; representative period; North Sea

\section{INTRODUCTION}

With the advancement in the field of numerical models, the predictions of morphological changes using process based models are in our reach. Process-based models are able to simulate the complex patterns of hydrodynamics due to currents and waves, sediment dynamics and morphodynamics. The modeling of short-term events covering days to months is usually performed with continuous updating of flow, waves, sediment transport and morphological changes. In this case the predictive ability is dependent to a large extent on the initial bathymetry and performance of the process based models.

Medium-term morphodynamic models covering periods of years incorporate input and process filtering techniques. Due to the fact that the morphodynamic model simulations are computationally time-consuming, such predictions must be accelerated for practical use. Several approaches have been used for the bottom updating of medium term morphodynamics. The earlier ones are based on the classical tide and wave averaging in combination with the continuity correction (Steijn 1992, Latteux 1995, Wilkens 2004, Mayerle and Zielke 2005). More recently, the 'online' or 'morphological factor' approach has been proposed in which a 'morphological factor' (Morfac) is applied to increase the depth change rates by a constant factor at each computational time step (Lesser et al. 2004; Roelvink 2006). The predictive ability of the models thus depends to a large extent on the proper selection of the representative conditions and periods for the site under investigation. Anthropogenic interventions often have a significant impact on flow and sediment patterns and their effect on coastal morphodynamics can be reasonably well predicted on the medium term. Morphological developments due to natural causes, however, are more difficult to trace and to simulate. Due to scarcity of bathymetric data on a regular time interval, such models are seldom calibrated or validated properly.

In this study, the predictive capability of a depth-averaged model in capturing the migration of a tidal channel on the German North Sea was investigated. Emphasis was given to the identification of the main sources of deficiency of the model in capturing the migration of the channel with good accuracy. The development phases of the models for simulation of flow, waves, sediment transport and morphological changes are presented. Calibration and validation of the process-based models were done using especially designed field measurements of water levels, current velocities, waves and suspended sediment concentrations with a dense spatial coverage. High resolution bathymetric measurements conducted at intervals of few months were used in the development and verification of the morphodynamic model. Results of the calibration and validation of the model covering the periods respectively from 2006 till 2008 and 2002 to 2006 are presented. Predictions of the migration of the tidal channel from 2008 to 2010 are given.

\footnotetext{
${ }^{1}$ Research and Technology Center Westcoast, University of Kiel, Otto-Hahn-Platz 3, 24118 Kiel, Germany
} 


\section{STUDY AREA}

The study concerns a tidal flat area 'Mittelplate' which is located on the German North Sea coast, about $100 \mathrm{~km}$ north of Hamburg (Fig. 1). The hydrodynamics and sediment dynamics in the region are driven by the combined effects of tides, waves and wind-induced currents. The semi-diurnal tide shows a mean tidal range of $3.2 \mathrm{~m}$, varying between $2.4 \mathrm{~m}$ at neap tides and $4.2 \mathrm{~m}$ at spring tides. The prevailing wind is from west to southwest directions. Maximum wave heights range about $3 \mathrm{~m}$ to $4 \mathrm{~m}$ along the edge of the tidal flats, with wave breaking along the outer margins of the area of interest (Mayerle and Zielke 2005). It was found that the mean grain size of bottom sediment in the area of investigation varies from $80 \mu \mathrm{m}$ to $230 \mu \mathrm{m}$. The sizes of sediment transported in suspension are about 1 to 5 times smaller than those at the seabed (Poerbandono and Mayerle 2005).
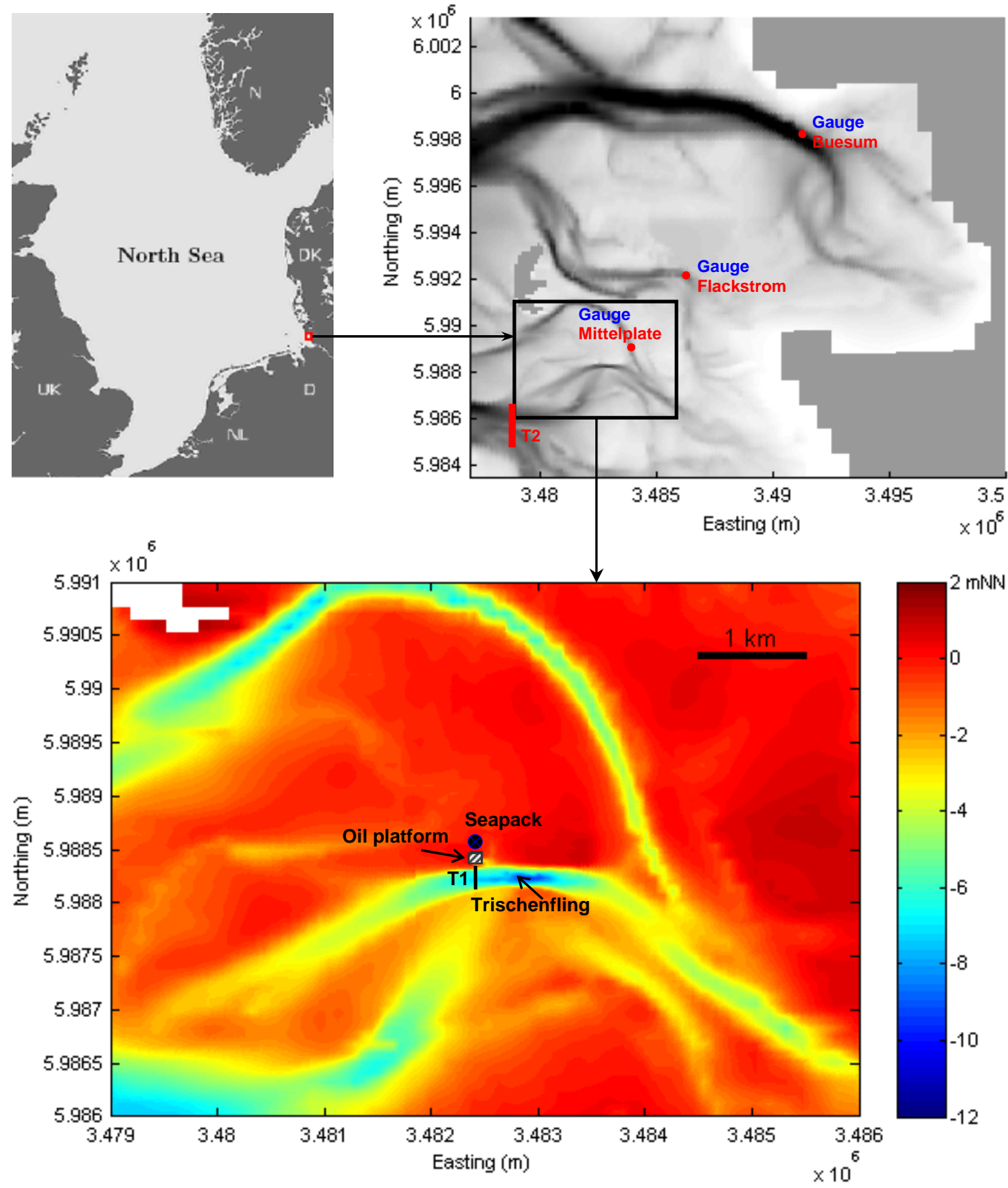

Figure 1. Study area. 
The tidal channel under investigation (see Trischenflinge in Fig. 1) with a maximum depth of about $12 \mathrm{~m}$ runs south of an offshore oil platform. The depths shown in the figure are relative to NN (Normal Null) which is the German Ordnance Datum or Mean Sea Level. The maximum current velocity in the tidal channel is in order of $1 \mathrm{~m} / \mathrm{s}$. The channel and the adjacent tidal flats are characterized by a very dynamic morphology as shown in Fig. 2. In the figure the evolution of the depth contour lines $-4 \mathrm{mNN}$ from 2006 until 2008 are shown. It can be seen that to the east of the oil platform the tidal channel experienced migration of up to about $50 \mathrm{~m} /$ year during this period. The movement of the western section of the channel is less pronounced especially concerning the northern bank of the channel. As a result of the scour protection measures at the platform, the migration of the channel section in front of the structure has ceased. Thus, to maintain approximately the same crosssectional area a slight deepening of this cross-section is observed to compensate for the ongoing migration of the southern sand bank.

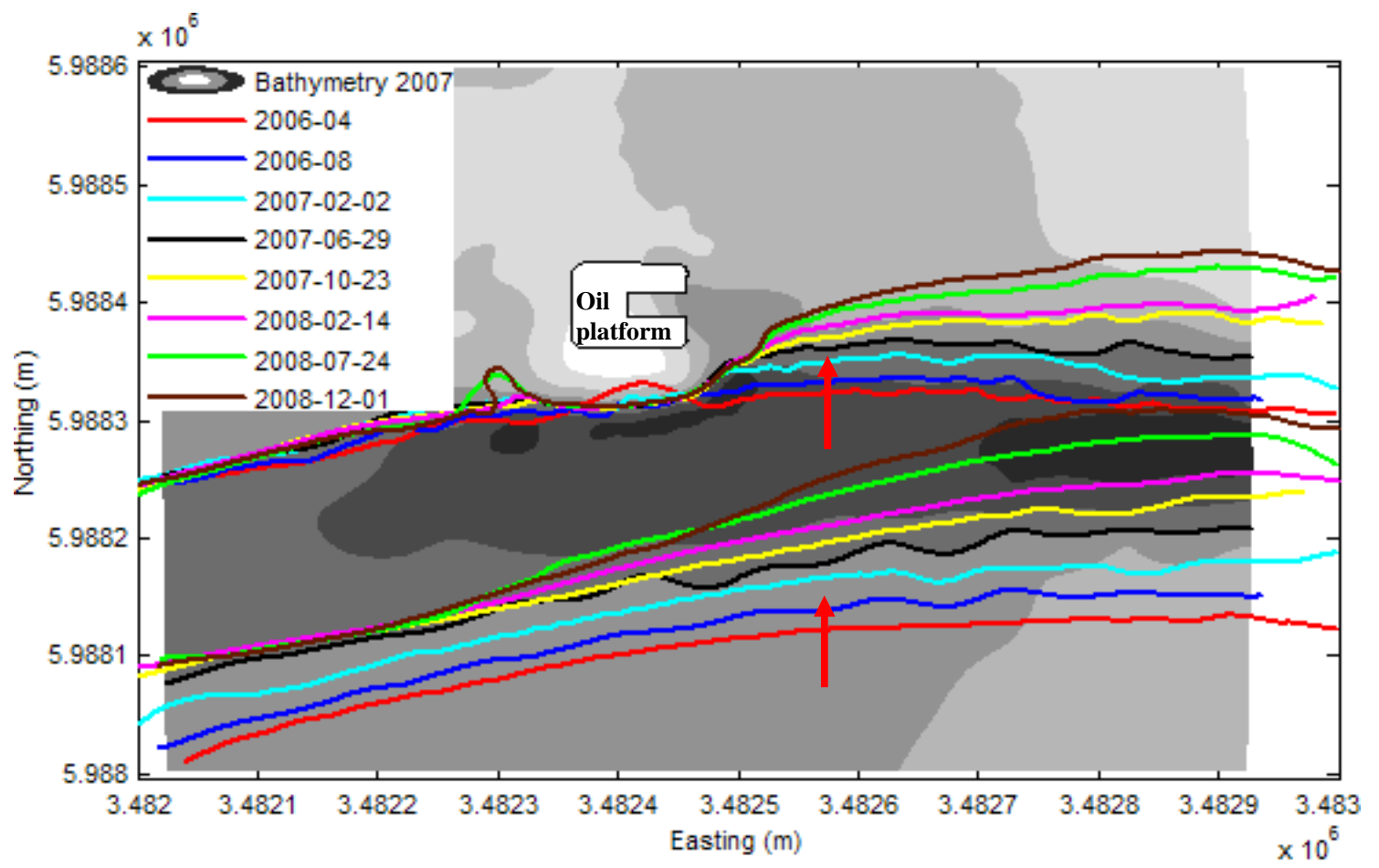

Figure 2. Migration of the tidal channel from 2006 till 2008.

\section{PROCESS BASED MODELS}

\section{Set-up}

Process-based models for simulation of flow, waves, sediment transport and morphological changes with a depth-averaged version of Delft3D modeling system were set-up for the study area (Lesser et al. 2004). The domain decomposition (DD) modeling technique implemented in Delft3D was applied. This is done to obtain good representation of the channel bathymetry through grid refinement and to reduce computational time by parallel computing. The model grid covers an area of about $370 \mathrm{~km}^{2}$. It includes two sub-domains with about the same number of grid cells (Fig. 3 ). The inner sub-domain covers the area of relevance including the relatively straight section of the Trischenflinge channel. The grid sizes of the outer sub-domain vary smoothly from about $300 \times 300 \mathrm{~m}$ away from the area of interest to $60 \times 60 \mathrm{~m}$ near the DD boundaries. The grid size in the inner subdomain is refined by factors of five and three along the south-north and west-east directions, respectively, resulting in the resolution of $12 \times 20 \mathrm{~m}$. The outer and inner sub-domains roughly consist of about 16,000 grid cells, making it well suited for parallel computing. 


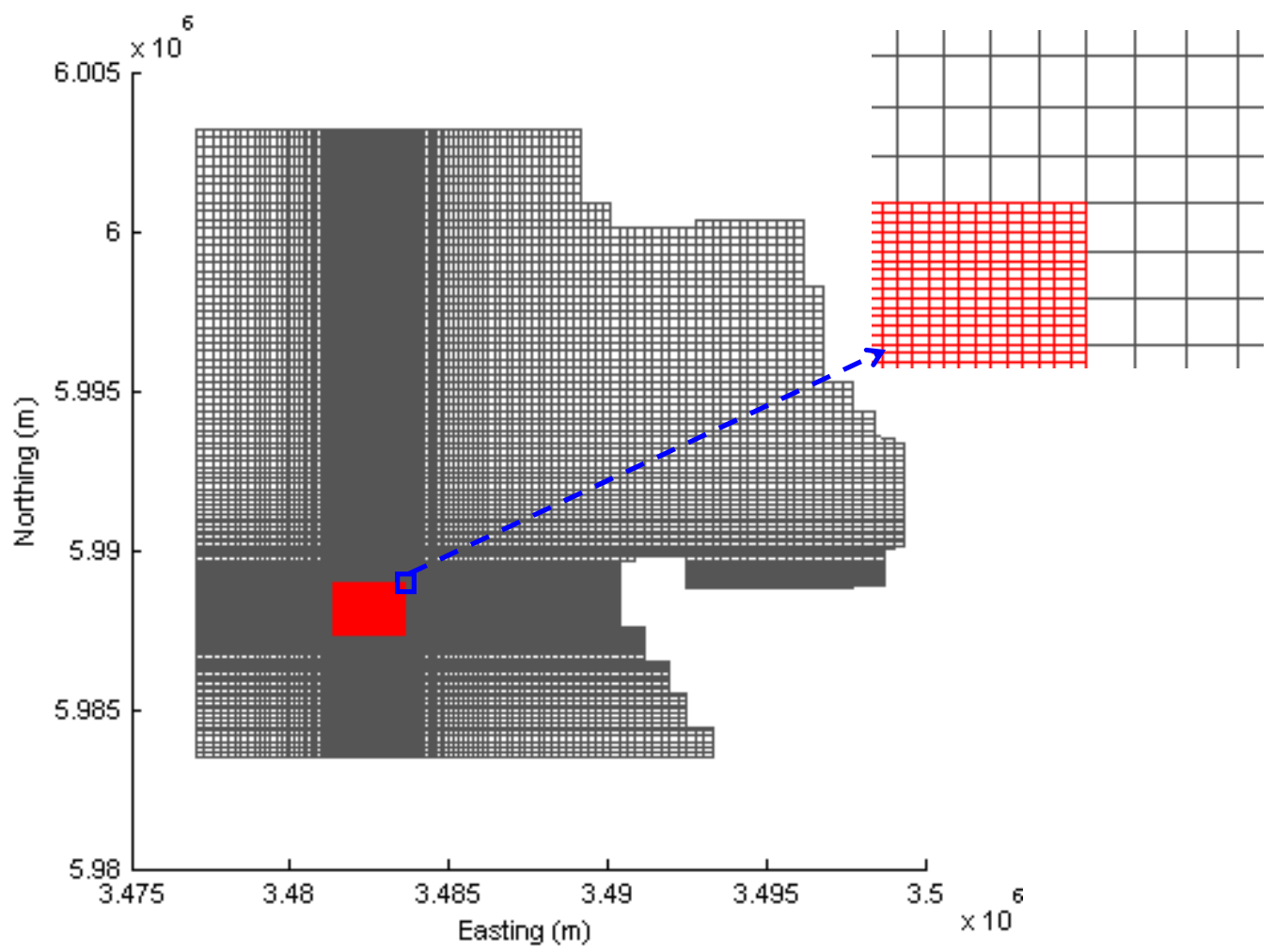

Figure 3. Mittelplate Model grid and detail of grid refinement.

The Mittelplate Model is driven by tidal and wave forcing at the open sea boundaries. The open sea boundary conditions for the flow and wave models are obtained according to the nesting sequence as shown in Fig. 4. The Mittelplate Model is nested in the German Bight Model, which is in turn nested in the Continental Shelf Model. The two latter models have been extensively calibrated and validated elsewhere (Mayerle and Zielke 2005). Wind forcing covering the entire Continental Shelf area is obtained from the COSMO-Model which has been developed at the German Weather Service (DWD) (Schättler et al. 2009).

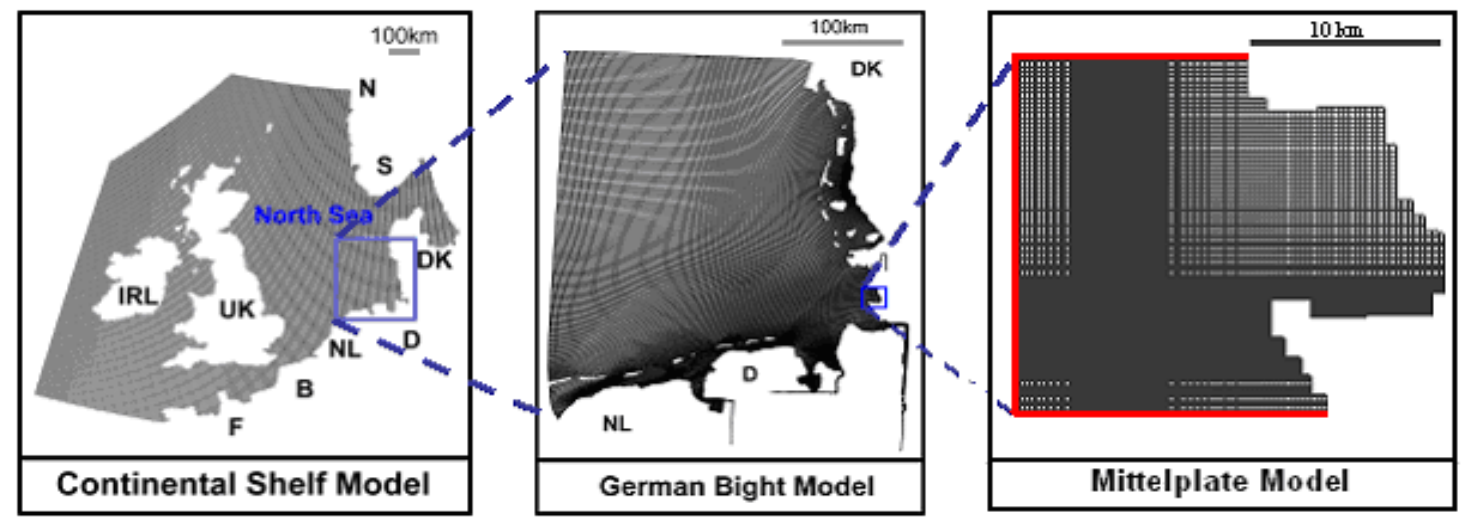

Figure 4. Nesting sequence for the generation of the open boundary conditions of the Mittelplate Model.

\section{Calibration and validation}

The process-based models were calibrated and validated against extensive sets of measured data of water levels, current velocities, waves and suspended sediment concentrations at several locations and cross sections within the domain. Calibration of the flow model was carried out by adjusting the bottom friction and eddy viscosity. The calibrated model was then validated using independent data 
sets not used for calibration. The results of the calibration and validation, here presented briefly, are in good agreement with measurements.

Fig. 5 shows typically the comparison between computed and observed water levels at the three gauges Buesum, Flackstrom and Mittelplate in the validation covering the entire month of November 2006. The location of the tidal gauges is shown in Fig. 1. The computed water levels at all stations fit very well with the measurements. Fig. 6 compares measured and modeled depth-averaged current velocities along the cross-section T1 (see Fig. 1 for the location). The comparisons are shown for low tide, high tide and during maximum flood and ebb currents on 20 February 2007 (spring tide). The measurements were taken with an acoustic device (ADCP) deployed from a moving vessel. The model results are in agreement with the measurements. The figure reveals that at this location, the flow is more predominant during ebb phase than flood phase.

Regarding the wave model, preliminary runs were carried out using default settings. The model results were then compared with the wave measurement data from a wave-measuring device (Seapack) installed on the tidal flat area, north of the oil platform (see Fig. 1). The model results prove to be quite consistent with the observations as shown in Fig. 7. Therefore, further calibration of the wave model was deemed unnecessary. With respect to the qualitative performance of the flow and wave models basing on RMAE (van Rijn et al. 2003), it is found that the models produce good results for current velocity (RMAE $<0.3)$ and for wave height $(\mathrm{RMAE}<0.1)$.

The sediment transport model was calibrated and validated using measurements of suspended sediment concentration and transport at several cross-sections of the tidal channels in the vicinity of the tidal channel under investigation. Profiles of suspended sediment concentrations were taken at several stations along defined cross-sections. The sediment characteristics in terms of percentage of mud and sand as well as the particle sizes of the sand fraction were also determined. The model was calibrated by adjusting the bed roughness and the critical shear stress of the mud fraction. Fig. 8 shows measured versus computed suspended sediment transport rates in $\mathrm{kg} / \mathrm{s}$ at cross-section T2 (see Fig. 1 for the location), over one tidal cycle on 01 July 2009. Positive and negative values respectively indicate the values during the flood and ebb phases. The results obtained show that the model is able to capture the cross-sectional variation of the sediment transport quite well.
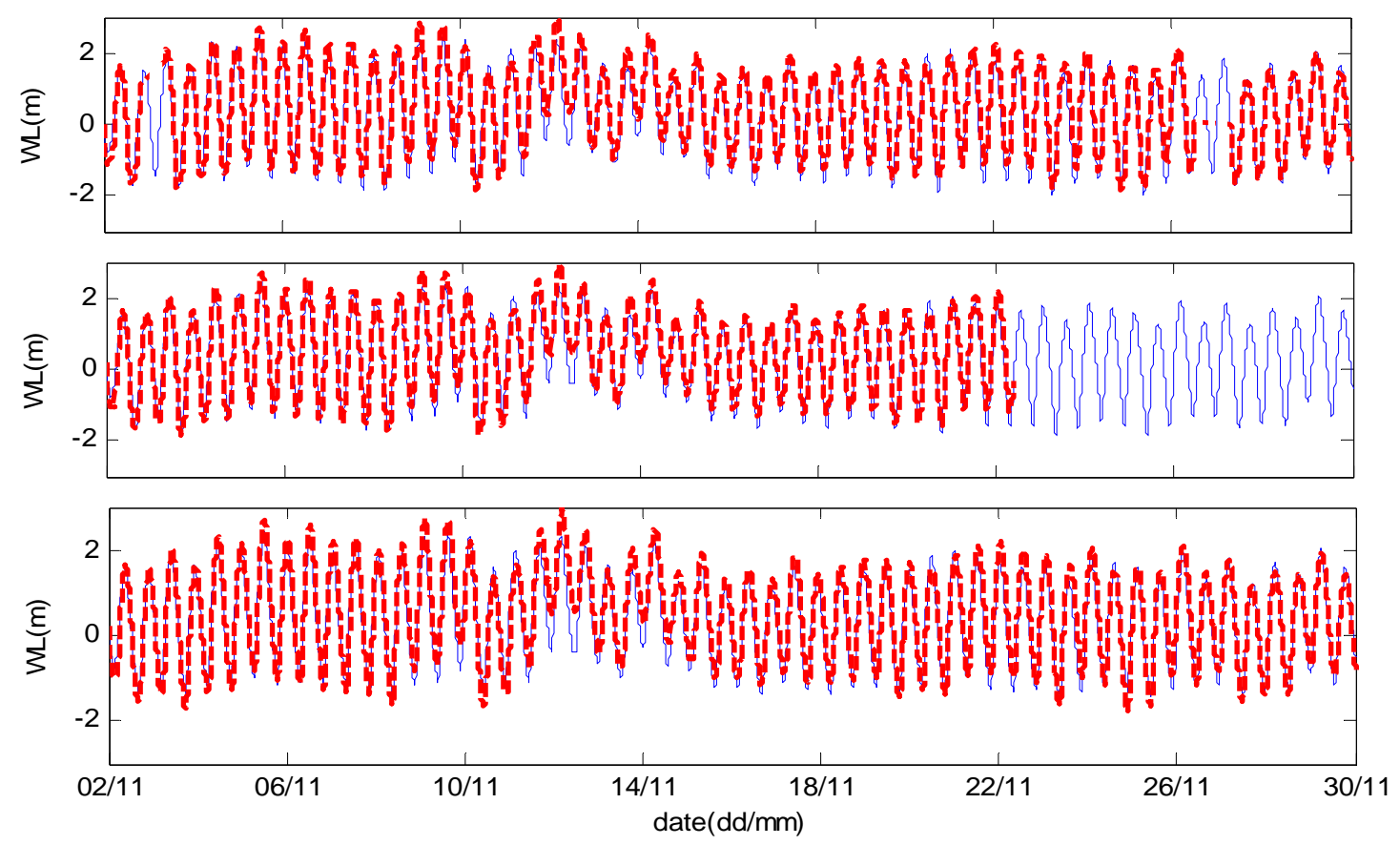

Figure 5. Measured (dotted lines) vs. computed (solid lines) water levels at gauges Buesum (top), Flackstrom (center) and Mittelplate (lower) (see Fig. 1 for the locations). 

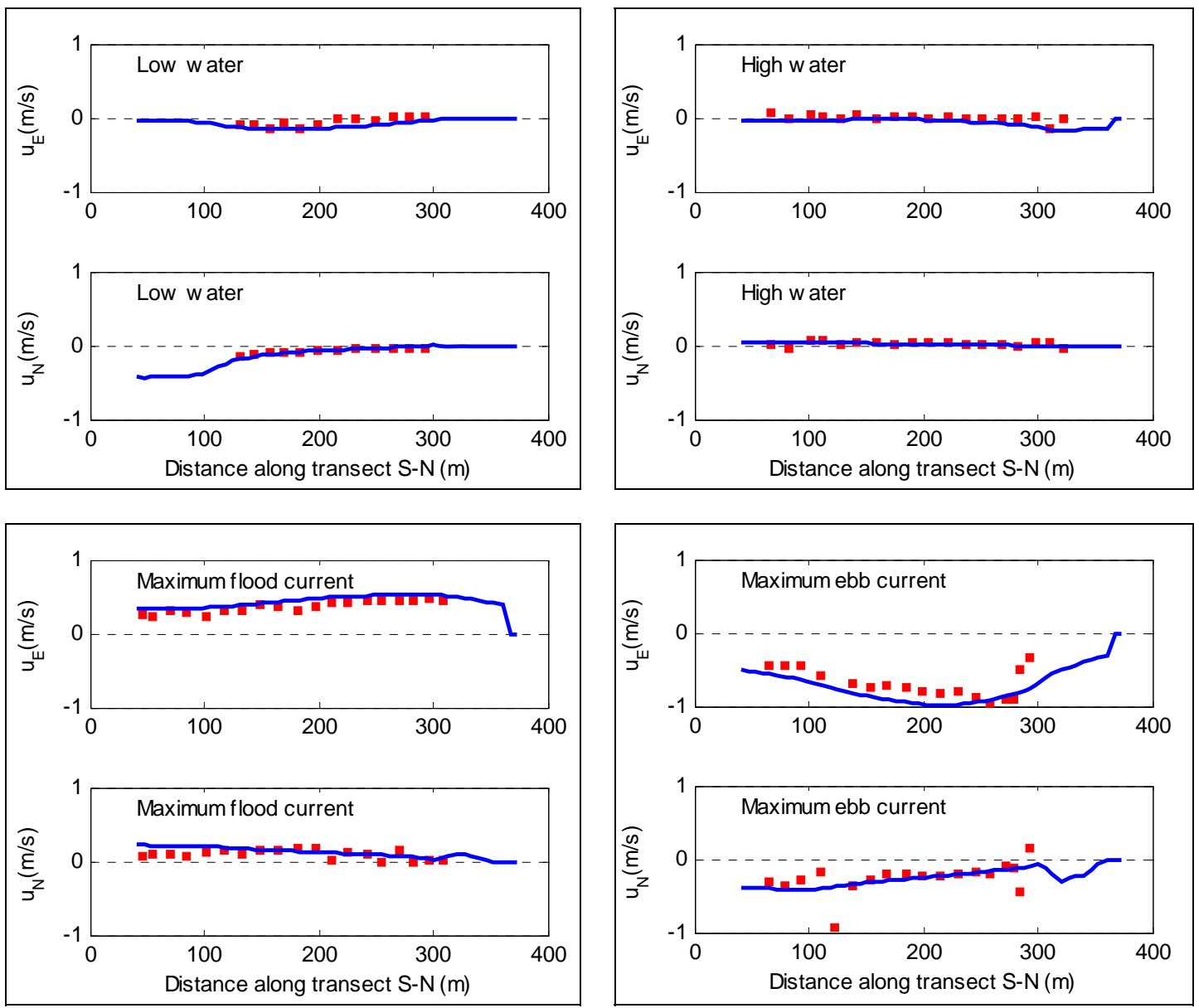

Figure 6. Measured (symbols) vs. computed (lines) variation of cross-sectional distribution of eastward ( $\left.u_{E}\right)$ and northward $\left(u_{N}\right)$ components of the current velocity at cross-section T1 on 20 February 2007- spring tide.

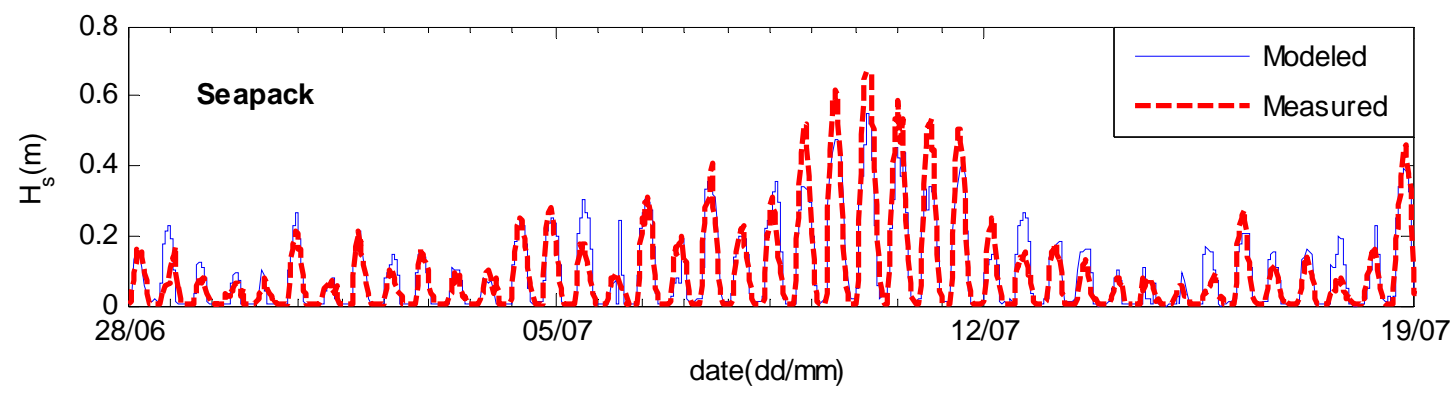

Figure 7. Measured vs. computed significant wave heights near the oil platform (Seepack location in Fig. 1)

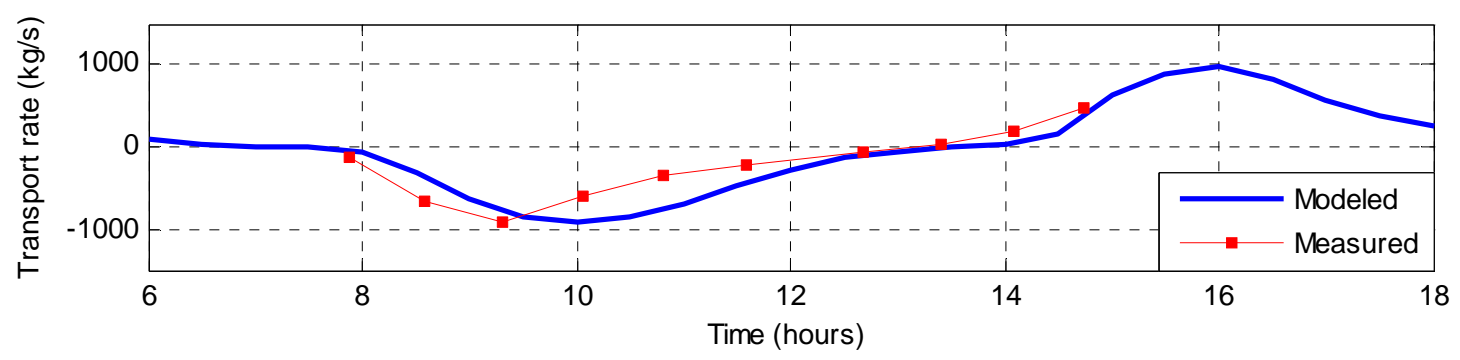

Figure 8. Measured vs. computed cross-sectional averaged suspended sediment transport at cross-section T2 on 01 July 2009. 


\section{MEDIUM-TERM MORPHODYNAMIC MODEL}

\section{Set-up}

The calibrated and validated process based models were used for setting-up the morphodynamic model for simulations on the medium-term. In this study, a morphological acceleration factor approach is used. This technique means that long morphological simulations can be achieved using hydrodynamic simulations of only a fraction of the required duration (Lesser et al. 2004). The selection of this fraction (representative period) is done using an approach proposed by Boon et al. (2002). The representative period is estimated on the basis of long term records of wind data typical to the study area. The following cost functions are determined:

$$
\begin{aligned}
& \mathrm{C} 1=\left(\mathrm{W}_{\mathrm{n}}-\mathrm{W}_{\mathrm{n} \_\mathrm{lt}}\right)^{2}+\left(\mathrm{W}_{\mathrm{e}}-\mathrm{W}_{\mathrm{e}_{-} \mathrm{lt}}\right)^{2} \\
& \mathrm{C} 2=\left(\sigma_{\mathrm{Wn}}-\sigma_{\mathrm{Wn} \_\mathrm{lt}}\right)^{2}+\left(\sigma_{\mathrm{We}}-\sigma_{\mathrm{We} \_\mathrm{lt}}\right)^{2} \\
& \mathrm{C} 3=\mathrm{C} 1 / \sigma_{\mathrm{C} 1}+\mathrm{C} 2 / \sigma_{\mathrm{C} 2}
\end{aligned}
$$

where $\mathrm{W}_{\mathrm{n}}$ and $\mathrm{W}_{\mathrm{e}}$ are the monthly averaged north and east wind components, respectively. $\mathrm{W}_{\mathrm{n} \_\mathrm{t}}$ and $\mathrm{W}_{\mathrm{e} \text { lt }}$ are the long-term averaged north and east wind components, respectively and $\sigma$ is the standard deviation. The representative period is defined by those pertaining to the lowest values of the cost function $\mathrm{C} 3$ which corresponds to periods in which the conditions resemble those of longer term used in the analysis. Based on the availability of the data, 12-year wind data from 1996 to 2008 was considered. The wind data is obtained from the application of the synoptic PRISMA model (Luthardt 1987) and from COSMO-Model. The representative periods are selected as the time windows yielding the smallest value of the cost function C3. Figs. 9 and 10 show the weighted curves of the C3 function respectively for one-month and two-month representative periods. To test the sensitivity of the morphological changes to the representative period, three representative one-month periods as indicated in Fig. 9 were selected for further analysis.

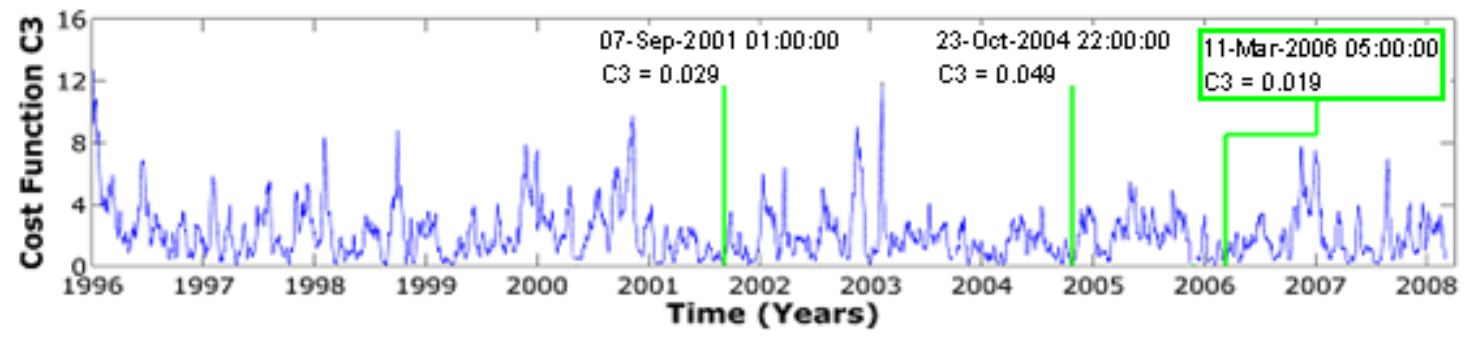

Figure 9. Weighted curve of the cost function C3 for one-month representative period

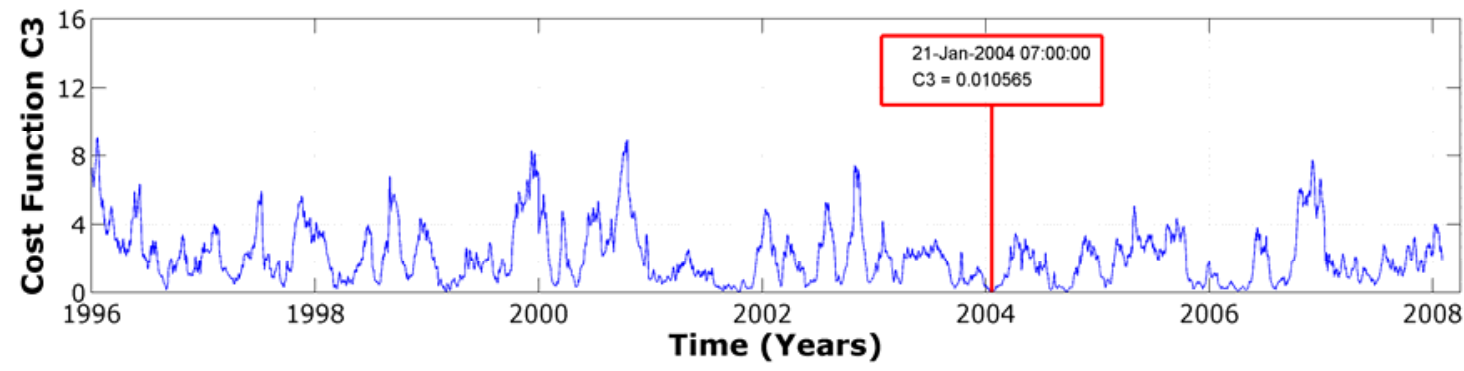

Figure 10. Weighted curve of the cost function C3 for two-month representative period.

\section{Sensitivity and Calibration}

Based on quality and availability of bathymetric data, the period 2006 to 2008 was selected for calibration of the morphodynamic model on the medium term. The one-month representative periods as shown in Fig. 9 were used in conjunction with a Morfac=24 to cover the two-year period of the simulation. The ability of the model in describing the morphological changes was tested at three crosssections as indicated in Fig. 11. The performance of the model relative to a baseline prediction is evaluated using the so-called Brier Skill Score (BSS) (Peet et al. 2002; van Rijn et al. 2003). This skill score compares the mean square difference between prediction and observation with the mean square difference between baseline prediction and observation as follows: 


$$
B S S=1-\left[\left\langle\left(\left|z_{b, c}-z_{b, m}\right|-\Delta z_{b, m}\right)^{2}\right\rangle /\left\langle\left(z_{b, 0}-z_{b, m}\right)^{2}\right\rangle\right]
$$

where $z_{b, m}$ is the measured bed level, $z_{b, c}$ is the calculated bed level, $z_{b, 0}$ is the initial bed level and $\Delta z_{b, m}$ is the error of measured bed level. The error involved in the bathymetrical measurements is also taken into consideration. Measurement errors equal to $0.1 \mathrm{~m}$ apply to field conditions. The initial bathymetry is used as the baseline prediction for the final bathymetry.

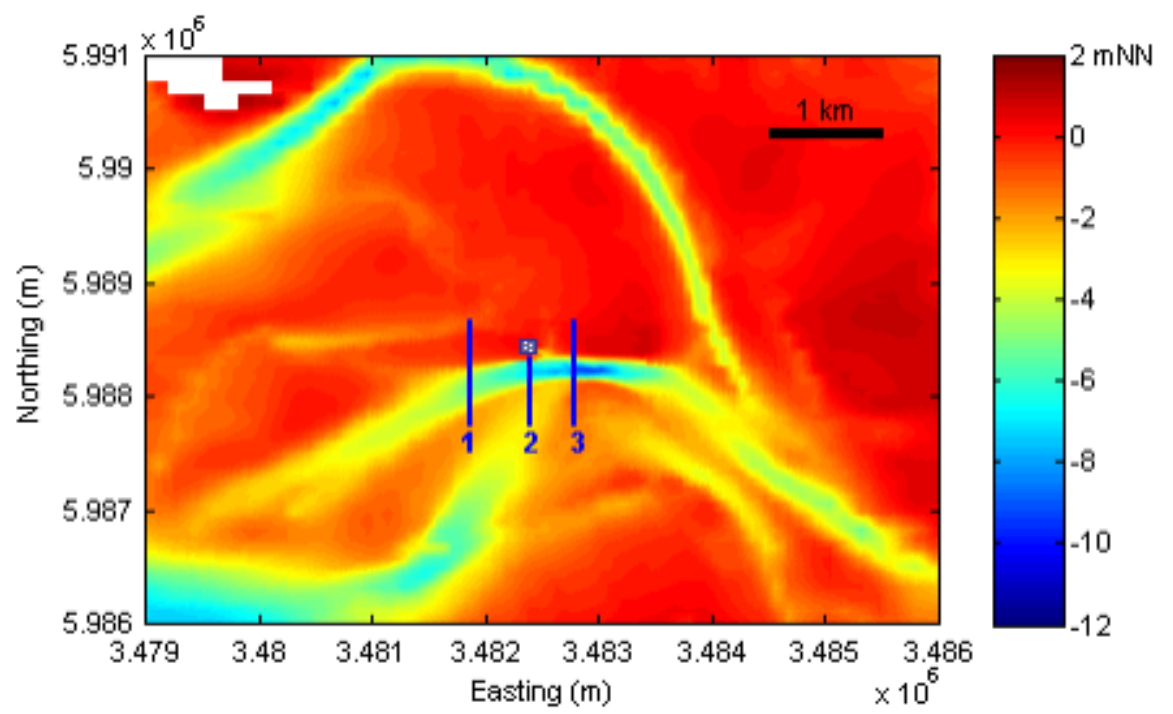

Figure 11. Cross-sections along the tidal channel chosen for checking the performance of the model

Several runs covering the period 2006 till 2008 considering different settings in terms of the particle sizes and transport equations were carried out initially. The performance of the transport formulas by van Rijn (1993) and Bijker (1971) and the critical shear stress values of the mud fraction were investigated. The results showed northward movement of the Trischenflinge channel similar to the observed ones. The sediment transport formulas and the critical shear stress of the mud fraction were found to have significant influence on the computed erosion-sedimentation pattern. Better agreement with measurements resulted with the van Rijn (1993) formulation. The effect of the particle sizes on the computed bed level was less significant for sizes ranging between $140 \mu \mathrm{m}$ and $200 \mu \mathrm{m}$.

The influence of the characteristics of the substrata in the vicinity of the tidal channel under investigation was also investigated. This was done by conducting simulations with and without the presence of a compacted cohesive layer which was detected near the oil platform at about -6 to $-8 \mathrm{mNN}$. The effect of this compacted layer on the bathymetrical development was well captured by the model. As a result the deepening of the channel was hindered and there was an intensification of the northward migration of the tidal channel in closer agreement with observations. Therefore simulations hereafter were carried out assuming the existence of the cohesive layer.

The influence of the representative period on the morphological changes was also investigated. Simulations considering the three periods with lowest values of the cost function $\mathrm{C} 3$, as indicated in Fig. 9, were carried out. The wind roses of the three best representative periods are compared in Fig. 12. Although certain differences with respect to the percentage of occurrence of the winds during the three periods can be seen, there is a clear dominance of the southwest wind direction, with wind speeds of about $5-10 \mathrm{~m} / \mathrm{s}$. Moreover, to a certain extend there is also agreement in terms of the winds from north-west.

Fig. 13 shows the comparison of the modeled bed elevations in 2008 as a result of the application of the three representative periods. It can be seen from the figure that nearly similar results are obtained when using the periods in 2004 and 2006. With the application of period in 2001, a second channel is formed at the western section of the channel. In addition, the eastern cross-section is shallower and the southern bank of the channel cross-section 2 in front of oil platform moves further northward compared to that obtained with the other two periods. An investigation of water levels in these three months showed that the water level pattern in terms of spring and neap time during the month in 2001 was different from those observed in 2004 and 2006. This may contribute to the differences. 
Fig. 14 shows the water levels and the significant wave heights at a location along the western boundary of the model for the best rated one-month representative period. It covers two full springneap cycles. Relatively calm weather conditions with significant wave heights generally lower than $1 \mathrm{~m}$ are observed in the first half of the month. During the second half, the waves are much stronger, reaching significant wave heights up to about $2 \mathrm{~m}$.

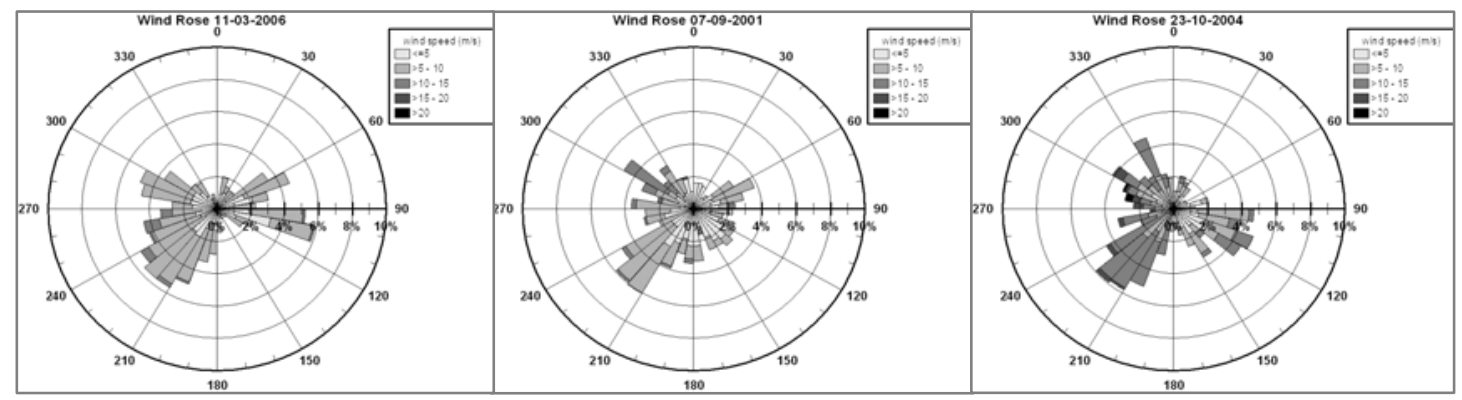

Figure 12. Wind roses for the three best one-month periods: March-April 2006 (left), September-October 2001 (center) and October-November 2004 (right).
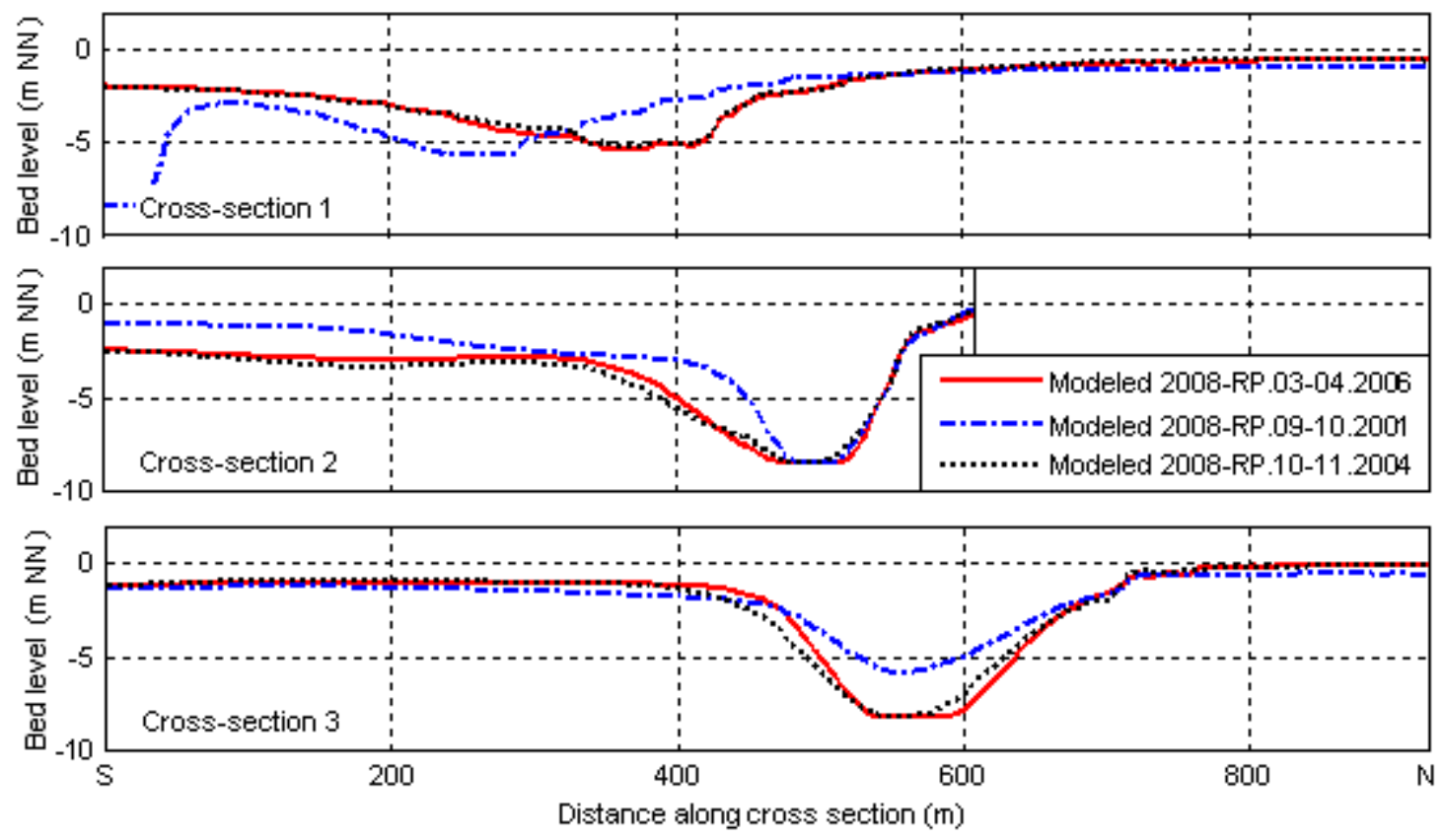

Figure 13. Comparison of computed bed profiles at selected cross-sections along the tidal channel applying three different representative periods.

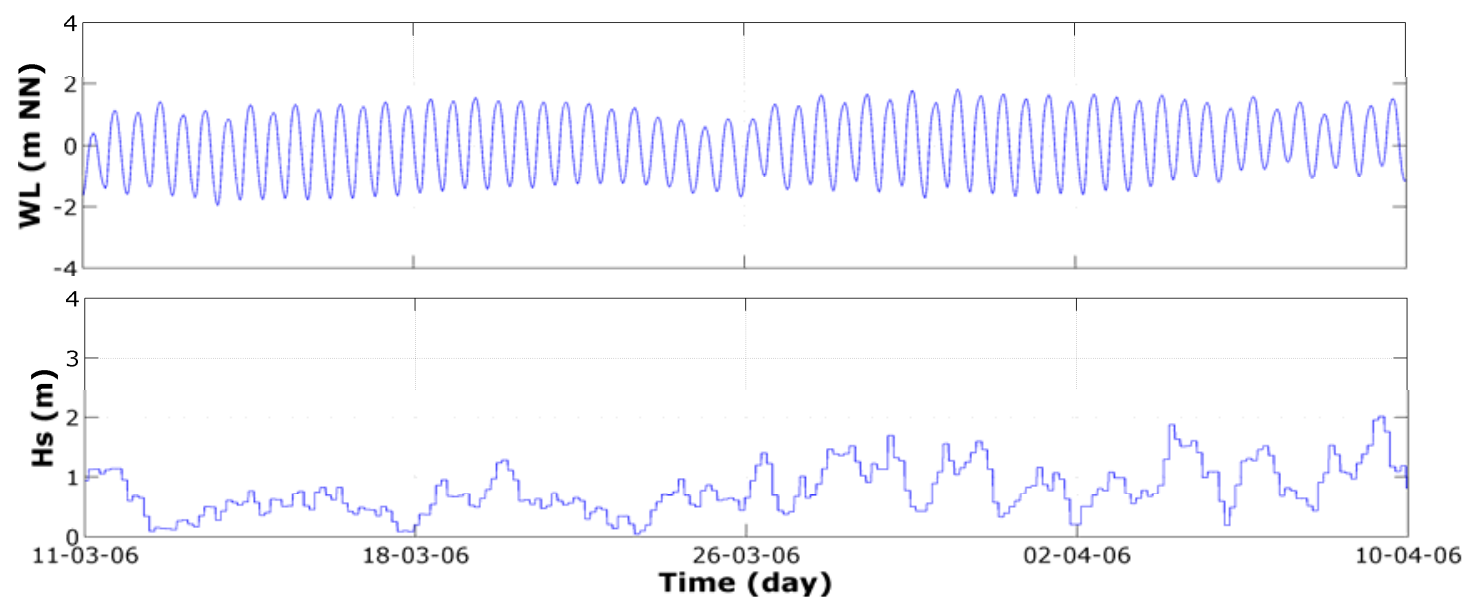

Figure 14. Water levels (upper) and significant wave heights (lower) for one-month representative period. 
The results of the calibration of the morphodynamic model are presented in Figs. 15 and 16. Fig. 15 shows the comparison of the measured and computed bed elevation profiles at cross-sections 1 , 2 and 3 (see Fig. 11). The morphological evolution corresponds quite well to the observed trends. The model is able to capture the migration at cross-sections 1 and 2 reasonably well. However, the predicted migration rate of the southern bank is slightly smaller than the observed one. The reason for that may be associated with the secondary flows (spiral motions), which were not accounted for in the current simulations. The deepening of the main tidal channel particularly at cross-section 2 is reasonably well captured. Notice that although the model is unable to describe the development of the two smaller channels sub-divided by a submerged bar, the depth of the channel after two years is in reasonable agreement with the observations. It is worth mentioning also that during this period, additional scour protection measures, not accounted for in the current simulations, were carried out at the oil platform. These measures might influence the flow and sedimentation-erosion patterns, especially in the vicinity of the oil platform. The BSS values vary between 0.35 and 0.9 , respectively corresponding to fair and excellent model performance according to the qualification by van Rijn et al. (2003). Fig. 16 shows the initial bathymetry in 2006 and the comparison of the modeled and observed bathymetries covering the near vicinity of the tidal channel in the year 2008 . The agreement in the development patterns of the tidal channels and flats is quite good.

\section{Validation}

Fig. 17 shows results of the validation of the model covering a four year period from 2002 to 2006. Notice that during this period the tidal channel is shallower than from 2006 to 2008. In this case the two-month representative period as indicated in Fig. 10 was used in conjunction with a Morfac $=24$. The model performance at cross-sections 1 (west of the platform) and 2 (at the platform) are between fair and good. At cross-section 3 (east of the platform) the agreement with observations in terms of the BSS score is good. In general the trends in terms of morphological developments are reasonably well captured by the model. The migration of the northern bank of the tidal channel is again in very good agreement with observation. Similarly to the model results for the calibration period, the rate of migration of the southern bank is lower than the observed one. In addition to the longer simulation period, the slight decrease in the model performance compared to the calibration period could be attributed also to the initial model bathymetry for the year 2002 which has been compiled on the basis of data sets covering different years.
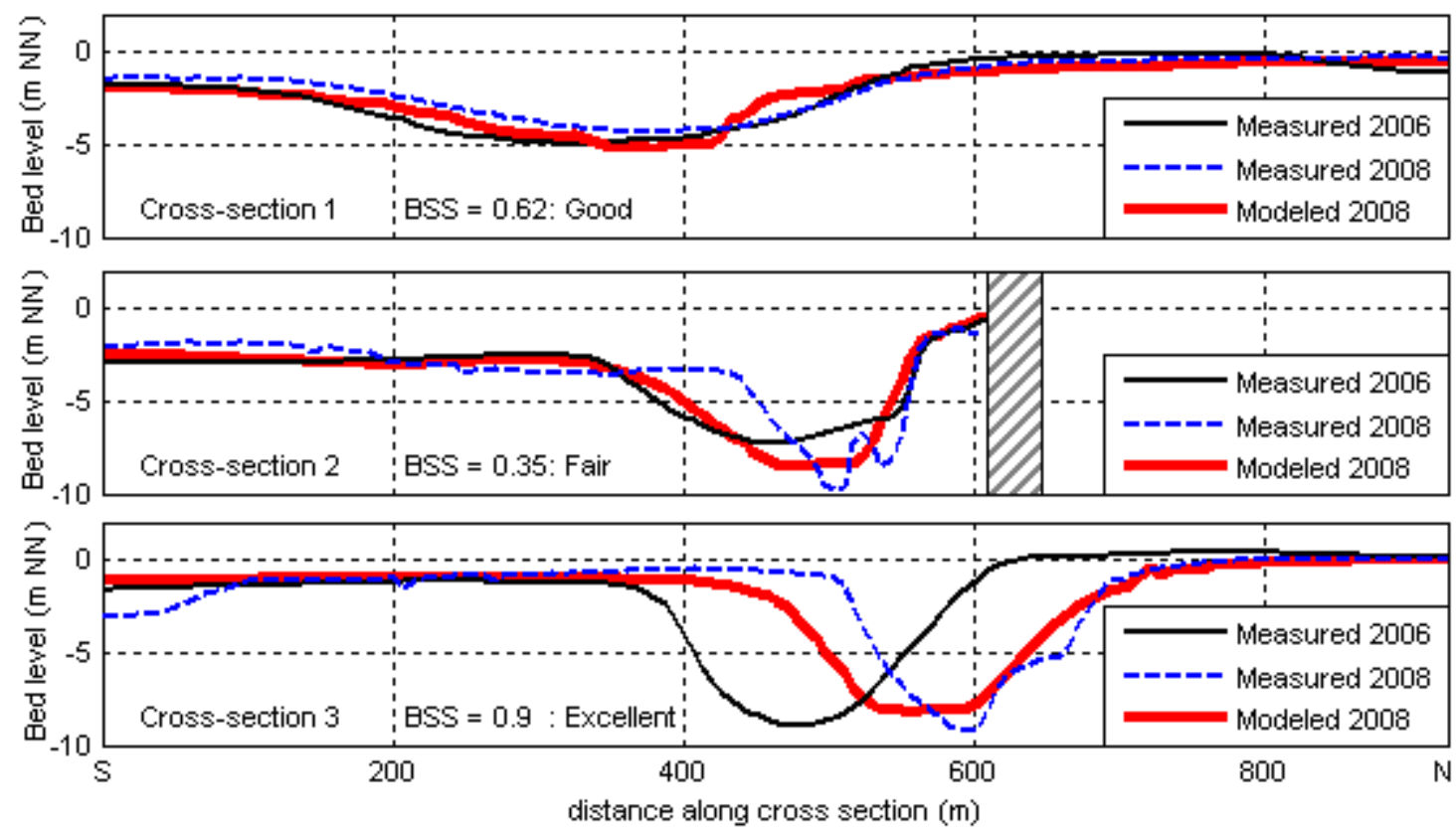

Figure 15. Measured vs. computed bed elevation profiles at selected cross-sections along the tidal channel for the calibration period 2006-2008. 


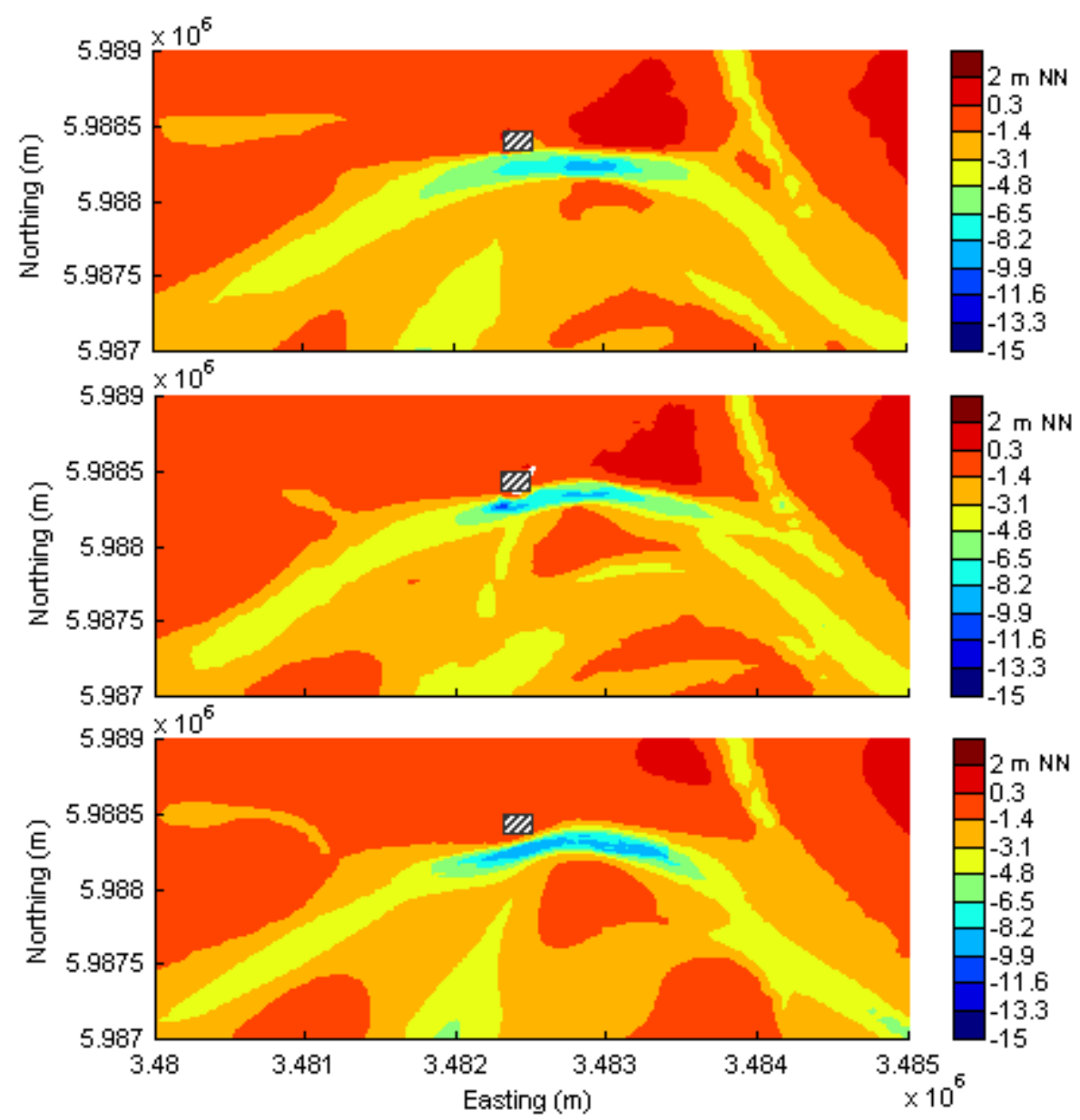

Figure 16. Observed bathymetry of 2006 (top), measured (center) and modeled (lower) bathymetries of 2008.

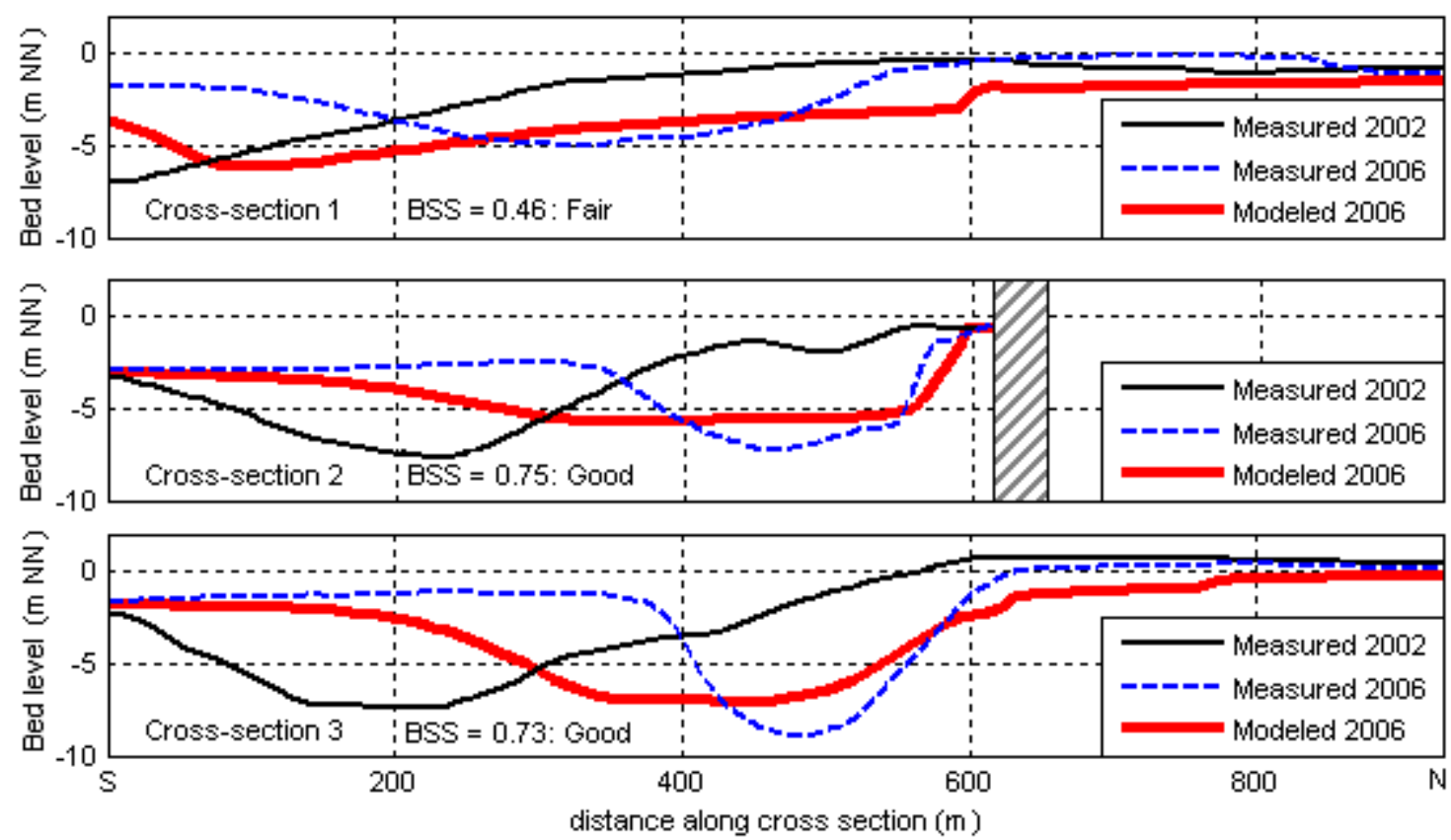

Figure 17. Measured vs. computed bed elevation profiles at selected cross-sections along the tidal channel for the validation period 2002-2006. 


\section{Prediction}

The results of the model calibration and validation provided a good degree of confidence in the model's ability to reproduce the morphological changes in the channel system. Predictions covering the period December 2008 to December 2010 were carried out. Although measurements are not yet available to check the model results, as the quality of the bathymetry of 2008 is reasonably good, the predictions obtained should be reasonably trustworthy. Fig. 18 presents the evolution of contour lines $-4 \mathrm{mNN}$ and $-2 \mathrm{mNN}$ during this period. A clear northward migration of the eastern section of the channel is predicted. However, compared to the migration rates predicted by the model during the calibration and validation periods, the predicted rates are considerably smaller. The channel tends to be shallower in the eastern and western sections of the tidal channel. Fig. 19 shows the migration of the eastern cross-section (cross-section 3) for the periods 2002 to 2006, 2006 to 2008 and 2008 to 2010. A change in the trend of migration is computed by the model from 2002 till 2008. It can be seen that an increase in the migration rate from about $35 \mathrm{~m} /$ year to $50 \mathrm{~m} /$ year respectively for the periods 2002 to 2006 and 2006 to 2008 is observed. A drop in the rate of migration to approximately $20 \mathrm{~m} / \mathrm{year}$ is predicted by the model from 2008 till 2010.

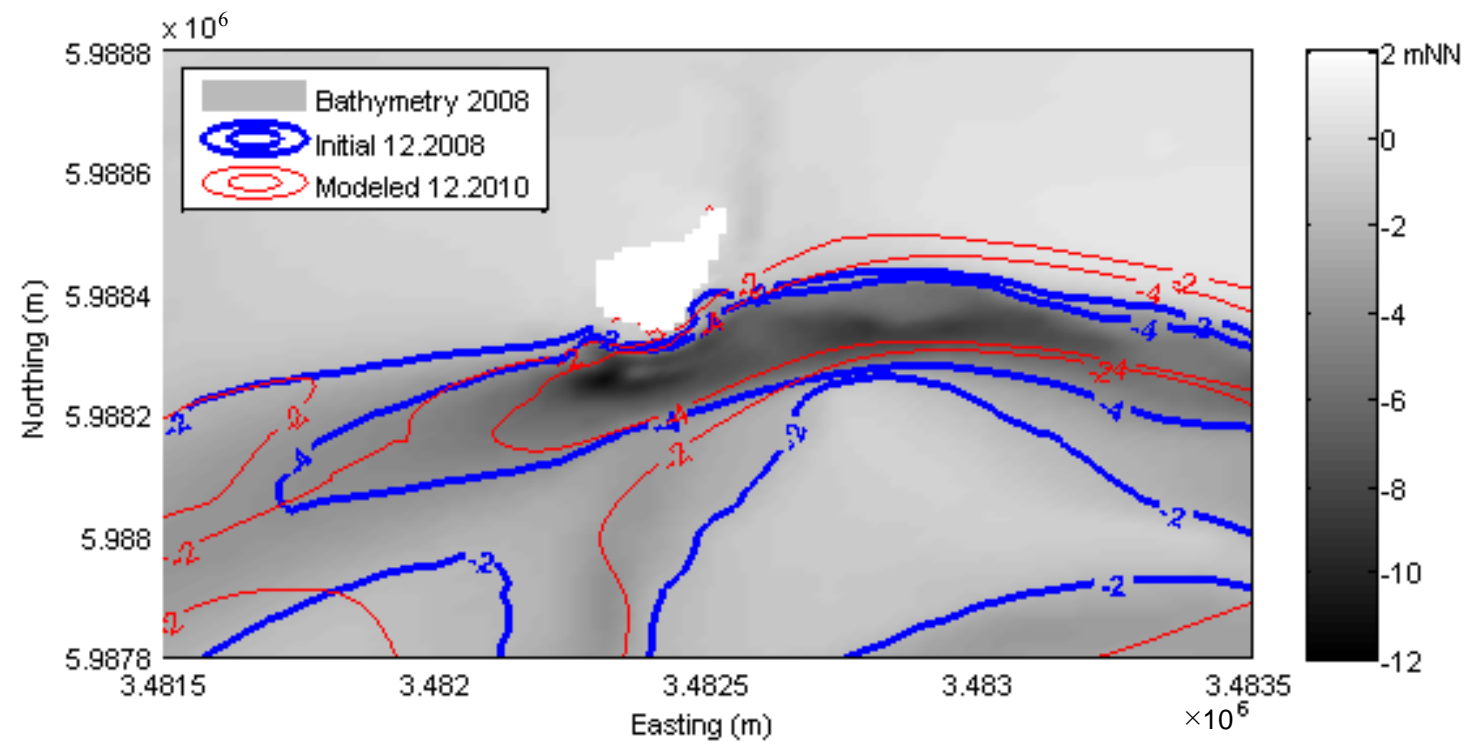

Figure 18. Evolution of contour lines $-4 m$ and $-2 m$ from December 2008 (bold) to December 2010 (thin).
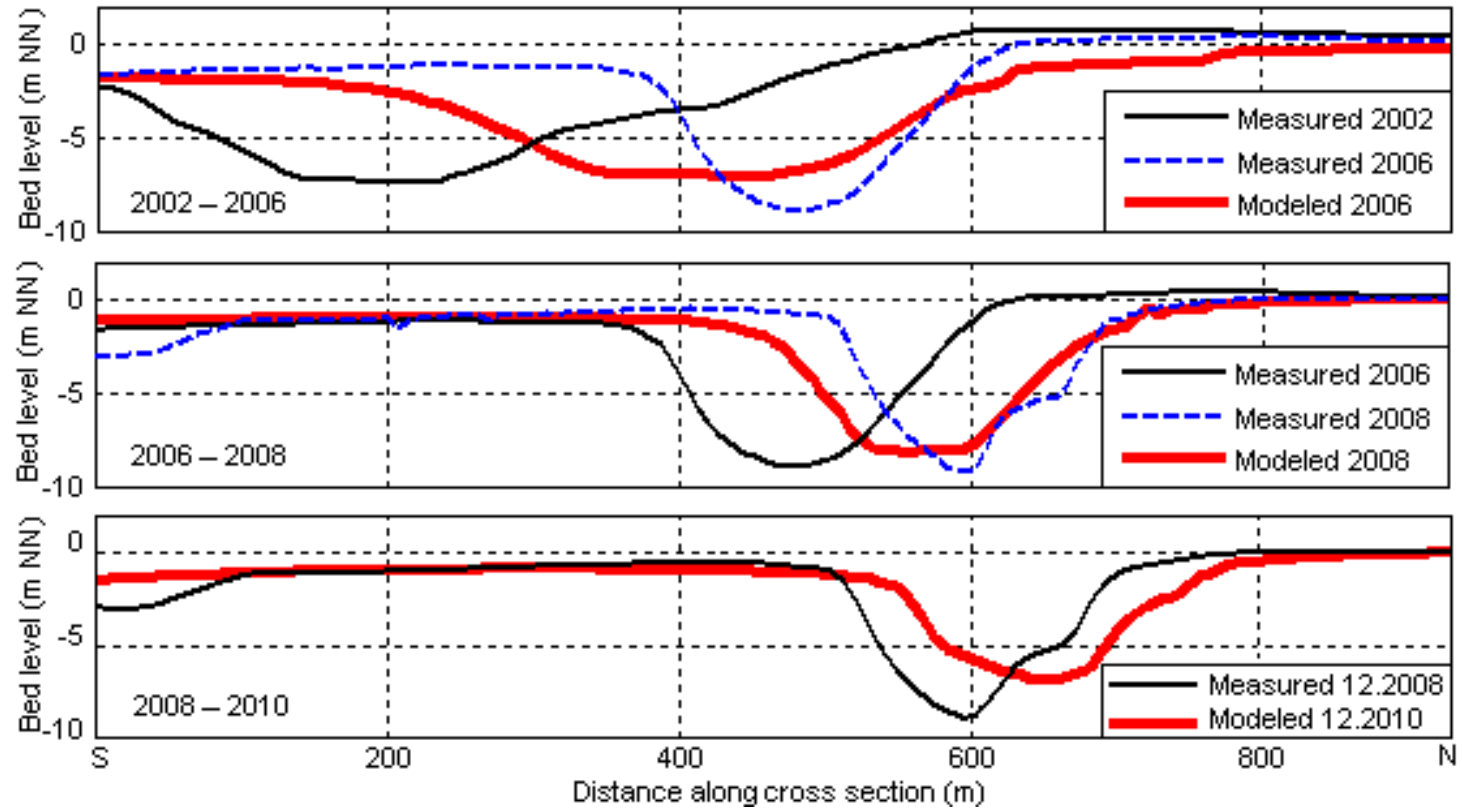

Figure 19. Migration of the cross-section 3 from 2002 till 2010 


\section{CONCLUSIONS}

This paper shows the applicability of the process-based model in capturing the migration of the channel and the cross-sectional developments reasonably well. The application of the domain decomposition technique proved to be quite effective for saving computational time. The availability of bathymetrical surveys at regular time intervals helped significantly in advancing the developments of such models. According to the Brier Skill Score the predictive ability of the morphodynamic model resulted between fair and excellent depending on the cross-sections and periods under examination.

It was found that the predictive ability of the model in capturing the rate of migration is dependent primarily on the starting bathymetry, the characteristics of the mud sediment fraction and of the substrata, and on the conditions during the representative period used in the simulations. The inclusion of a compacted cohesive sediment layer in the model setup was found to have a major effect on the rate of migration of the tidal channel. A more detailed investigation about the characteristics of the underground is pursued. As the approach used for selection of representative periods is such that extreme events are generally excluded, its influence on the morphological developments of the channel on the medium term should be examined in more detail. We recommend enhancing the selection of the representative conditions by taking into account the water levels and resulting sediment transport rates. Analysis of the results of online simulations using Morfac $=1$ with those obtained using different acceleration factors are currently underway.

Regarding the migration of the tidal channel, the analysis of the rates of migration from 2002 till 2010 showed that there has been a change in trends. Whereas an increase in the rate of migration was observed from 2002-2006 to 2006-2008, the model predictions from 2008 till 2010 show a clear reduction. Investigations are currently underway to figure out the reasons for that.

\section{ACKNOWLEDGMENTS}

The authors wish to thank the RWE Dea for the financial support and for providing the measurement data for the development of the models.

\section{REFERENCES}

Boon, J., H. Kerkamp, and L. Dardengo. 2002. Alternative dumping sites in the Ems-Dollard estuary, WL | Delft Hydraulics Report, Z3328.

Latteux, B. 1995. Techniques for Long-Term Morphological Simulation under Tidal Action, Marine Geology, 126, 129-141.

Lesser, G.R., J.A. Roelvink, J.A.T.M. van Kester, and G.S. Stelling. 2004. Development and validation of a three-dimensional morphological model. Coastal Engineering, 51, 883-915.

Luthardt, H. (1987). Analyse der Wassernahen Druck- und Windfelder über der Nordsee aus RoutineBeobachtungen, Hamburger Geophysikalische Einzelzeitschriften, A83, in German.

Mayerle, R. and W. Zielke. 2005. Predictions of Medium Scale Morphodynamics: Promorph Project Overview, Die Küste, 69, 1-23.

Peet, A.H., J. Sutherland, and R.L. Soulsby. 2002. Skill Assessment in Coastal Models. HR Wallingford.

Poerbandono and R. Mayerle. 2005. Composition and Dynamics of Sediments in Tidal Channels of the German North Sea Coast, Die Küste, 69, 63-91

Roelvink, J.A. 2006. Coastal morphodynamic evolution techniques. Coastal Engineering, 53, 277-287.

Schättler, U., G. Doms, and C. Schraff. 2009. A Description of the Nonhydrostatic Regional COSMOModel. Part VII: User's Guide. Deutscher Wetterdienst.

Steijn, R.C. 1992. Input Filtering Techniques for Complex Morphological Models, Delft Hydraulics Report, H824.53.

Van Rijn, L.C., D.J.R. Walstra, B. Grasmeijer, J. Sutherland, S. Pan, and J.P Sierra. 2003. The predictability of cross-shore bed evolution of sandy beaches at the time scale of storms and seasons using process based profile models. Coastal Engineering, 47, 295- 327.

Wilkens, J. 2004. Medium Scale Morphodynamics of the Central Dithmarschen Bight, PhD thesis, University of Kiel, Germany. 